\title{
A MERENDA ESCOLAR DOS ALUNOS DAS QUATRO PRIMEIRAS SERIES DE NIVEL I DAS ESCOLAS DA REDE MUNICIPAL DE ENSINO DE SÃO PAULO, BRASIL*
}

Ondina Rosenburg**

RSPUB9:394

RosenBLRi, O. A merenda escolar dos alunos das quatro primeiras séries de nivel I das escolas da Rede Manicipal de Ensino de Sáo Paulo, Brasil. Rev. Saúde públ., S. Pallo, 12:55-66, 1978.

Resumo: Foi estudada uma populafáo de 380 alunos das quatro primeiras séries de nivel l, das escolas da Rede Municipal de Ensino de Sáo Paulo (Brasil) com a finalidade de analisar o valor nutricional da merenda escolar bem como o seu papel como refeição substitutiva ou complementar do desjejum domiciliar. Os resultados desse foram: 1") a média do consumo de calorias foi igual a $13,50 \%$ das necessidades diárias, de acordo com a idade e o sexo, e o consumo mais treqülente foi de $15 \mathrm{~L}-20 \%$ dessas necessidades; 2") a média do consumo de protcinas foi igual a $28,64 \%$ das necessidades diárias, e o consumo mais freqüente foi de $25 \mathrm{I}-30 \%$ dessas necessidades; $3^{\prime \prime}$ a média do consumo de lipides foi de 10,36 gramas e o consumo mais freqüente foi de 10 1- 20 gramas; 4") a composiça centesimal da merenda, nos seus valores médios, caracterizon-se por uma distribuiça ho harmoniosa dos nutrientes e por uma inter-relaçâo mais equilibrada do que a observada no desjejum.

Unitermos: Escolares, nutriçäo. Nutrição, S. Paulo, Brasil. Merenda escolar. Desjejum.

\section{INTRODLCÃO}

As primeiras Esculas Municipais de São Paulo foram instaladas em 1955. En 1960, estas escolas iniciaram uma assistência alimentar, depois de constatado o comparecimento de alunos em completo jejum.

Para facilitar a implantaçào de novos programas alimentares, em 1967 foi criado () Departamento de Assistencia Escolar, du qual faz parte a Divisão de Assistência em Nutrição. Segundo Naclei (1970), o objetivo desta Divisão, para todas as criancas matriculadas nas Escolas Municipais é "fornecer alimentação sratuita supletiva para cobrir $1 / 4$ das necessidades alinenta- res diárias yuanto a proteinas, gorduras, hidratos de carbono, total calórico, sais minerais e vitaminas".

As metas referentes ao numero de criancas a serem assistidas pelos programas de alimentação da Prefeitura de São Paulu foram atingidas. Todavia, segundo Rosenburgll (1972), a qualidade da merenda distribuida ainda muito se afasta do ideal proposto, isto é, o de proporcionar a cada escolar o equivalente a $1 / 4$ das suas necessiclades alimentares diárias. Esse mesmo traballu mostra yue, apesar das res-

\footnotetext{
* Parte da tese de Doutoramento apresentad a à Faruldade de Saúde Pública da LtSP, em 1976.

** Do Departamento de Saúde Materno-Infantil da Faculdade de Saúde Publacat da USP - Ar. Dr. Arnaldo, 715 - São Paulo. SP - Brasil.
} 
ROSENBURG, O. A merenda escolar dos alunos das quatro primeiras séries de nivel I das escolas da Rede Municipal de Ensino de São Paulo, Brasil. Rev. Saúde públ., S. Paulo, 12: $55-66,1978$.

triçōes, a merenda vem exercendo papel eficaz sobre o estado de nutrição dos alunos das Escolas Municipais de São Paulo. O Programa de Alimentação Escolar, destinado às crianças provenientes de famílias de haixa condição sócio-econômica, desenvolvido pela Prefeitura Municipal, no ano de 1968, estimulou o aumento de peso e de estatura da maioria dos escolares.

Existem, entretanto, outros aspectos, sob os quais a importancia da merenda deve ser enfatizada.

Em trabalho anterior:2, vimos que o contingente de 104.638 crianças matriculadas nas Unidades Municipais de Ensino, no periodo da manhã, vai à escola após um ronsumo insuficiente de alimentos, ou sem qualquer alimento. Ao descrever a refeição escolar oferecida paralelamente a estas crianças, procuramos chamar a atencão sobre a atuação mais imediata da merenda, ou seja, substituindo o desjejum, quando ele ' omitido, ou complementando-o, quando é insuficiente. Destacamos assim a influência da merenda, no sentido de evitar o jejum prolongado e conseqüente sensação de fome nas horas matinais, as quais, para os alunos que freqüentam a Unidade pela manhã, coincidem com as do trabalho escolar.

\section{POPULACAO E MÉtODOS}

As merendas estudadas foram as oferecidas, no ano de 1974, nas escolas da Rede Municipal de Ensino, a 380 alunos

Os métodos utilizados foram descritos no trabalho sobre desjejum, cuja pesquisa foi realizada concomitantemente à da merenda escolar (Rosenburg'12, 1977).

\section{R. FESULTADOS}

\subsection{Cobertura calórica e protidica da merenda em relação às necessidades diárias}

\subsubsection{Valores Médios}

A cobertura calórica e protidica da merenda, em termos de necessidades diárias, segundo a idade e sexo, e em percentual, deu os resultados constantes das Tabelas 1 e 3 , respectivamente, em relação à média, para as crianças do estudo e para os três grupos de regionais.

TA B ELA 1

Valnr médio da cobertura calórica da merenda $(\%)$ em relação às necessidades diárias Crianças do estudo e zonas urbanas.

\begin{tabular}{l|c|c|c}
\hline \multicolumn{1}{c}{ População } & Média $(\%)$ & Desvio Padrão & No de crianças \\
\hline Crianças do estudo & 13,5 & 5,5 & 380 \\
Zona periférica & 12,9 & 5,8 & 201 \\
Zona intermediáriá & 14,1 & 5,1 & 162 \\
Zona central & 15.4 & 6.2 & 17 \\
\hline
\end{tabular}

\subsubsection{Distribuiçäo das criaņ̧as do estudo}

A distribuição das crianças, segundo essa cobertura pode ser verificada nas Tabelas 2 e 4.
A Tabela 2 mostra que o maior número de eventos se colocou na classe $15 \mid-20 \%$, e que para $100 \%$ das crianças do estudo, o consumo foi inferior a $1 / 4$ das necessidades diárias. 
ROSENBURG, O. A merenda escolar dos alunos das quatro primeiras séries de nível I das escolas da Rede Municipal de Ensino de São Paulo, Brasil. Rev. Saúde puibl., S. Paulo, 12: $55-66,1978$.

\section{TAB E L A 2}

Distribuiçăo do número, percentagem e percentagem acumulada das crianças do estudo segundo a cobertura calórica da merenda $(\%)$ em relação às necessidadesı diárias.

\begin{tabular}{|c|c|c|c|c|}
\hline \multirow{2}{*}{ Cobertura } & \multirow{2}{*}{ calórica $(\%)$} & \multicolumn{2}{|c|}{ Crianças } & \multirow{2}{*}{$\begin{array}{c}\text { Percentagem } \\
\text { acumulada }\end{array}$} \\
\hline & & $n^{0}$ & $\%$ & \\
\hline 0 & $1-5$ & 53 & 13,9 & 13.9 \\
\hline 5 & -10 & 38 & 10,0 & 23,9 \\
\hline 10 & $1-15$ & 109 & 28,7 & 52,6 \\
\hline 15 & $1-20$ & 155 & 40,8 & 93,4 \\
\hline 20 & -25 & 25 & 6,6 & 100,0 \\
\hline Total & & 380 & 100.0 & 100,0 \\
\hline
\end{tabular}

TABE L A 3

Valor médio da cobertura protídica da merenda (\%) em relação às necessidades diárias -. Crianças do Estudo e zonas urbanas.

\begin{tabular}{l|r|r|r}
\hline \multicolumn{1}{c|}{ População } & Média $(\%)$ & Desvio padrão & $\begin{array}{c}\text { No de } \\
\text { crianças }\end{array}$ \\
\hline Crianças do estudo & 28,6 & 13,0 & 380 \\
Zona periférica & 26,7 & 12,9 & 201 \\
Zona intermediária & 30,4 & 13,1 & 162 \\
Zona central & 33,9 & 8,0 & $\mathbf{1 7}$ \\
\hline
\end{tabular}

TAB E L A 4

Distribuição do número, percentagem e percentagem acumulada das Crianças do Estudo segundo a cobertura protidica da merenda (\%) em relação às necessidades diárias.

\begin{tabular}{|c|c|c|c|c|}
\hline \multirow{2}{*}{ Cobertura } & \multirow{2}{*}{ protídica $(\%)$} & \multicolumn{2}{|c|}{ Crianças } & \multirow{2}{*}{$\begin{array}{c}\text { Percentagem } \\
\text { acumulada }\end{array}$} \\
\hline & & ne & $\%$ & \\
\hline 0 & $1-5$ & 21 & 5,5 & $\mathbf{5 , 5}$ \\
\hline 5 & $1-10$ & 8 & 2,1 & 7,6 \\
\hline 10 & -15 & 27 & 7,1 & 14,7 \\
\hline 15 & -20 & 32 & 8,4 & 23,2 \\
\hline 20 & $1-25$ & 50 & 13.2 & 36.3 \\
\hline 25 & -30 & 71 & 18,7 & 55,0 \\
\hline 30 & $-\quad 35$ & 48 & 12,6 & 67,6 \\
\hline 85 & $-\quad 40$ & 52 & 13,7 & 81,3 \\
\hline 40 & -45 & 31 & 8,2 & 89,5 \\
\hline 45 & -50 & 20 & 5,3 & 94,7 \\
\hline 50 & $-\quad 55$ & 20 & 5,3 & 100,0 \\
\hline Total & & 380 & 100,0 & 100,0 \\
\hline
\end{tabular}


ROSENBURG, O. A merenda escolar dos alunos das quatro primeiras séries de nível $I$ das escolas da Rede Municipal de Ensino de São Paulo, Brasil. Rev. Saúde públ., S. Paulo, 12: $55-66,1978$.

Pela Tabela 4 verifica-se que, em $36,3 \%$ dos casos, a cobertura protídica foi inferior a $25 \%$ das necessidades diárias e que, em conseqüência, em $63,7 \%$ dos mesmos, essá cobertura foi igual ou superior a $1 / 4$ dessas necessidades. O número mais freqüente de eventos - 71 - encontra-se na classe $25-30 \%$ de cobertura.

\subsection{Valores absolutos do consumo de calorias e de nutrientes da merenda}

Os resultados dos cálculos relativos aos valores absolutos do consumo de calorias, proteinas, glicides e lipides encontram-se na Tabela 5.

A distribuiçâo das crianças do estudo, segundo o consumo de calorias, e de proteínas pode ser verificada nas Tabelas 6 e 7 , respectivamente.

Nota-se na Tabela 6 que o numero mais freqüunte de eventos está situado na faixa de $300-400$, onde se encontra a média, igual a 315,24 calorias.

Conforme a Tabela 7 , a freqüência maior de eventos situa-se na faixa $10 \mid-15$ gramas, correspondendo a um contingente de $46,3 \%$ dos escolares da amostra, en-

TABEL A

Valores minimos, máximos, médios $(m)$, desvios-padrão ( $s$ ). amplitude de variação e coeficiente de variação de Pearson $(\%)$ das calorias e nutrientes (em gramas) - Crianças do Estudo.

\begin{tabular}{l|c|c|c|c|c|c}
\hline \multicolumn{1}{c|}{ Consumo } & $\mathrm{m}$ & $\mathrm{s}$ & $\begin{array}{c}\text { Amplitude de } \\
\text { variação }\end{array}$ & min. & max. & $\begin{array}{c}\text { Coefjciente de } \\
\text { variação de } \\
\text { Pearson } \\
(\%)\end{array}$ \\
\hline Calorias & 315,2 & 124,4 & 426.6 & 65,9 & 492,5 & 39.5 \\
Proteinas & 11.9 & 4.9 & 19.5 & 0,2 & 19.7 & 44,1 \\
Glicides & 44,2 & 18,8 & 66.7 & 0,1 & 66.8 & 42,6 \\
Lípides & 10.4 & 4,8 & 18.1 & 0,2 & 18,3 & 46.6 \\
\hline
\end{tabular}

TA B ELA 6

Distribuição do número, percentugem e perentagem acumulada das Crianças do Estudo serunde a comsmo de cialorias.

\begin{tabular}{|c|c|c|c|c|}
\hline \multirow{2}{*}{\multicolumn{2}{|c|}{ Calorias }} & \multicolumn{2}{|c|}{ Criancas } & \multirow{2}{*}{$\begin{array}{c}\text { Percentagem } \\
\text { acumulada }\end{array}$} \\
\hline & & n" & $\%$ & \\
\hline & $1-100$ & 33 & 8.7 & 8,7 \\
\hline 100 & $1-200$ & 58 & 15.3 & 23,9 \\
\hline 200 & $1-300$ & 45 & 11,8 & 35,8 \\
\hline 300 & $1-4000$ & 126 & 33,2 & 68,9 \\
\hline 400 & $1-500$ & 118 & 31,1 & 100,0 \\
\hline \multicolumn{2}{|l|}{ Total } & 380 & 100,0 & 100,0 \\
\hline
\end{tabular}


ROSENBURG, O. A merenda escolar dos alunos das quatro primeiras séries de nivel I das escolas da Rede Municipal de Ensino de $\mathrm{S}$ ão Paulo, Brasil. Rev. Saúde públ., S. Paulo, 12: $55-66,1978$.

\section{TA B E L A 7}

Distribuição do número, percentagem e percentagem acumulada das Crianças do Estuds segundo o consumo de proteínas (em gramas)

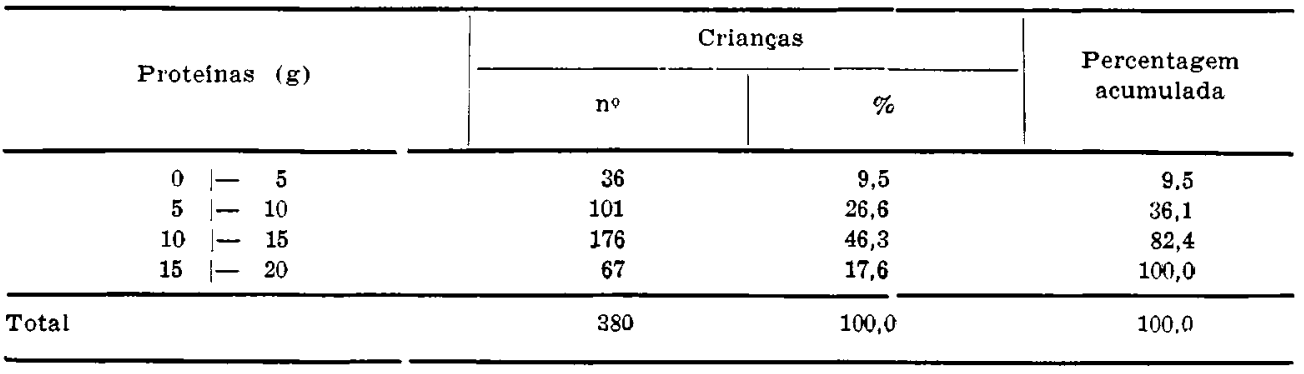

quanto a média $(11,9 \mathrm{~g})$ encontra-se na classe correspondente à moda.

A distribuição da população, segundo o consumo de glícides, encontra-se na Tabela 8.

Verifica-se que a frequência maior de eventos se situa na faixa $40 \mid-60$ gramas, na qual se encontra também a média, igual a $44,16 \mathrm{~g}$.

$\mathrm{Na}$ Tabela 9 pode-se verificar a distribuição da população segundo o consumo de lipides.

TABELA 8

Distribuição do número, percentagem e percentagem acumulada das Crianças do Estudo segundo o consumo de glicides (em gramas).

\begin{tabular}{|c|c|c|c|c|}
\hline \multirow{2}{*}{\multicolumn{2}{|c|}{ Glicides (g) }} & \multicolumn{2}{|c|}{ Crianças } & \multirow{2}{*}{$\begin{array}{c}\text { Percentagem } \\
\text { acumulada }\end{array}$} \\
\hline & & no & $\%$ & \\
\hline 0 & $1-$ & 49 & 12,9 & 12.9 \\
\hline 20 & - & 57 & 15,0 & 27,9 \\
\hline 40 & -60 & 185 & 48,7 & 76,6 \\
\hline 60 & $i-80$ & 89 & 23,4 & 100,0 \\
\hline Total & & 380 & 100.0 & 100.0 \\
\hline
\end{tabular}

TABLA 9

Distribuição do número, percentagem e percentagem acumulada das Crianças do Estudo segundo o consumo de lipides (em gramas).

\begin{tabular}{|c|c|c|c|c|}
\hline \multirow{2}{*}{\multicolumn{2}{|c|}{ Lipides (g) }} & \multicolumn{2}{|c|}{ Crianças } & \multirow{2}{*}{$\begin{array}{l}\text { Percentagem } \\
\text { acumulada }\end{array}$} \\
\hline & & ne & $\%$ & \\
\hline 0 & $1-10$ & 172 & 45,3 & 45,3 \\
\hline & -20 & 208 & 54,7 & 100,0 \\
\hline Total & & 380 & 100,0 & 100.0 \\
\hline
\end{tabular}


ROSENBURG, O. A merenda escolar dos alunos das quatro primeiras séries de nível I das escolas da Rede Municipal de Ensino de São Paulo, Bragil. Rev. Saúde públ., S. Paulo, 12 $55-66$. 1978 .

Verifica-se que a moda se situa na faixa 10 - 20 gramas, correspondendo a $54,7 \%$ da população. A média, igual a $10,36 \mathrm{~g}$, é portanto coincidente com a classe da moda.

\subsection{Composição centesimal da merenda}

Os resultados da composição centesimal da merenda encontram-se nas Tabelas 10 a 13 .

A distribuição das crianças do estudo segundo a contribuição calórica centesimal do componente glicídico encontra-se na Tabale 11 .

Segundo os dados da Tabela 11, em apenas $30,01 \%$ dos casos, os glícides contribuiram com $60 \%$ ou mais das calorias totais. Em nenhum caso esse componente representou $100 \%$, ou seja, a totalidade das calorias.

Para o componente protidico, a distribuição das crianças do estudo encontra-se na Tabela 12.

T A B E L A 10

Composição Centesimal - Valores médios (m), mínimos (min.), máximos (max.), desviospadrão (s), amplitude de variação e coeficiente de variação de Pearson (\%) Crianças do Estudo

\begin{tabular}{|c|c|c|c|c|c|c|}
\hline $\begin{array}{l}\text { Percentagem } \\
\text { calórica }\end{array}$ & $\mathrm{m}$ & $\mathrm{s}$ & $\begin{array}{l}\text { Amplitude de } \\
\text { variação }\end{array}$ & $\min$. & $\max$ & $\begin{array}{l}\text { Coeficiente de } \\
\text { variação de } \\
\text { Pearson }(\%)\end{array}$ \\
\hline Glícides & 55,4 & 17.9 & 90.0 & 7,5 & 97,5 & 32.3 \\
\hline Prótides & 14.5 & 5,6 & 30,6 & 0.6 & 31.3 & 38,8 \\
\hline Lípides & 30.1 & 12.5 & 60,7 & 1.7 & 62,4 & 41.6 \\
\hline
\end{tabular}

T A B E L A 11

Composição Centesimal - Distribuição do número, percentagem e percentagem acumulada das Crianças do Estudo segundo o componente glicídico,

\begin{tabular}{|c|c|c|c|c|c|}
\hline & \multirow{2}{*}{\multicolumn{2}{|c|}{$\begin{array}{l}\text { Percentagem } \\
\text { cal. glícides }\end{array}$}} & \multicolumn{2}{|c|}{ Crianças } & \multirow{2}{*}{$\begin{array}{c}\text { Percentagem } \\
\text { acumulada }\end{array}$} \\
\hline & & & ne & $\%$ & \\
\hline & 0 & $1-\quad 10$ & 19 & 5,0 & 5,0 \\
\hline & & $1-\quad 20$ & 8 & 2,1 & 7.1 \\
\hline & & $1-\quad 30$ & - & - & 7,1 \\
\hline & 30 & $1-\quad 40$ & 19 & 5,0 & 12,1 \\
\hline & 40 & $1-\quad 50$ & 87 & 22,9 & 35,0 \\
\hline & 50 & $1-\quad 60$ & 133 & 35,0 & 70,0 \\
\hline & 60 & $1-$ & 84 & 22,1 & 92,1 \\
\hline & 70 & $1-$ & 2 & 0.5 & 92,6 \\
\hline & & $1-\quad 90$ & 6 & 1,6 & 94.2 \\
\hline & & $1-100$ & 22 & 5,8 & 100,0 \\
\hline Total & & & 380 & 100,0 & 100,0 \\
\hline
\end{tabular}


ROSENBURG, O. A merenda escolar dos alunos was quatro primeiras séries de nfvel I das escolas da Rede Municipal de Ensino de Säo Paulo, Brasil. Rev. Saúde públ., S. Paulo, 12: 55-66, 1978.

TA B E L A 12

Distribuição do número, percentagem e percentagem acumulaca das Crianças do Estudo segundo o componente protídico.

\begin{tabular}{|c|c|c|c|c|}
\hline \multirow{2}{*}{\multicolumn{2}{|c|}{$\begin{array}{l}\text { Percentagem } \\
\text { cal. proteínas }\end{array}$}} & \multicolumn{2}{|c|}{ Crianças } & \multirow{2}{*}{$\begin{array}{l}\text { Percentagem } \\
\text { acumulada }\end{array}$} \\
\hline & & no & $\%$ & \\
\hline 0 & - 5 & 22 & 5,8 & 5,8 \\
\hline 5 & -10 & 5 & 1,3 & 7,1 \\
\hline & - 15 & 226 & 59,5 & 66,6 \\
\hline & -20 & 100 & 26,3 & 92,9 \\
\hline & -25 & 8 & 2,1 & 95.0 \\
\hline & - 30 & - & - & 95,0 \\
\hline & $1-35$ & 19 & 5,0 & 100.0 \\
\hline Total & & 380 & 100,0 & 100,0 \\
\hline
\end{tabular}

Nota-se na Tabela 12 que a frequiência maior de "evètintös correspondente a $59,47 \%$ da população encontra na faixa 10 - $15 \%$ de contribuição calórica relativa a prótides.
Contribuição inferior a $10 \%$ encontra-se em apenas $12,87 \%$ đos casos.

Para o componente lipídico, a distribuição das crianças do estudo foi a constante da Tabela 13.

TA B E A 13

Distribuição do número, percentagem e percentagem acumulada das Crianças do Estudo segundo o componente lipidico.

\begin{tabular}{|c|c|c|c|c|}
\hline \multirow{2}{*}{\multicolumn{2}{|c|}{$\begin{array}{l}\text { Percentagem } \\
\text { cal. lipides }\end{array}$}} & \multicolumn{2}{|c|}{ Crianças } & \multirow{2}{*}{$\begin{array}{l}\text { Percentagem } \\
\text { acumulada }\end{array}$} \\
\hline & & n\% & $\%$ & \\
\hline 0 & $1-5$ & 24 & 6,3 & 6,3 \\
\hline 5 & $1-10$ & 4 & 1,0 & 7.4 \\
\hline 10 & -15 & 2 & 0,5 & 7,9 \\
\hline & -20 & - & - & 7,9 \\
\hline 20 & $1-25$ & 64 & 16,8 & 24,7 \\
\hline 25 & $1-30$ & 108 & 28,4 & 53,1 \\
\hline 30 & $1-35$ & 83 & 21,8 & 75,0 \\
\hline 35 & $1-40$ & 49 & 12,9 & 87.9 \\
\hline 40 & $1-45$ & 19 & 5,0 & 92,9 \\
\hline 45 & $1-50$ & - & - & 92,9 \\
\hline 50 & |- 55 & - & - & 92.9 \\
\hline 55 & $1-60$ & - & - & 92,9 . \\
\hline 60 & $1-65$ & 27 & 7,1 & 100,0 \\
\hline Total & & 380 & 100,0 & 100,0 \\
\hline
\end{tabular}


ROSENBURG, O. A merenda escolar dos alunos das quatro primeiras séries de nivel I das escolas da Rede Municipal de Ensino de São Paulo, Brasil. Rev. Saúde príbl., S. Paulo, 12: $55-66,1978$.

Figura - Composição centesimal do desjejum e da merenda (Ano 1974) representação gráfica

(\%)

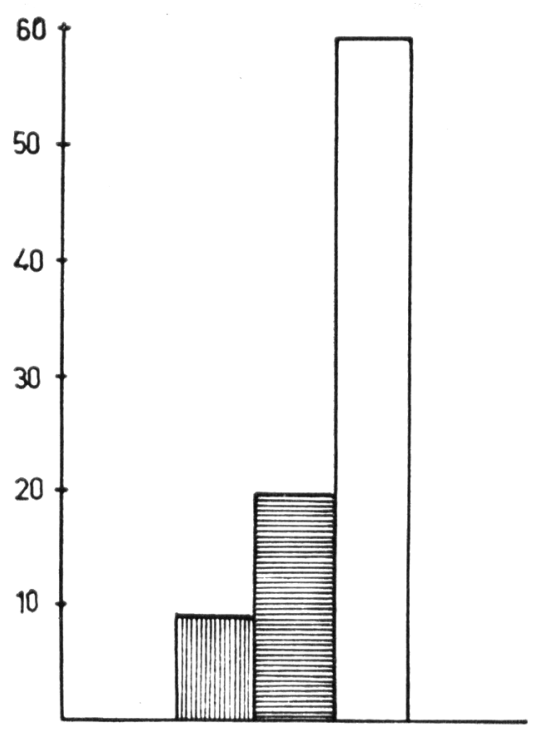

Drótides
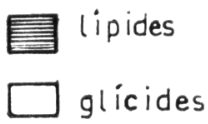

DESJEJUM - Composição centesimal: Valores médios dos nutrientes básicos das Crianças do Estudo.

Nota-se na Tabela 13 que a moda se acha na classe correspondente a $25-30 \%$, com $28,42 \%$ dos componentes da amostra.

Em $47,86 \%$ dos casos, a contribuição calórica centesimal dos lipides foi igual ou superior a $30 \%$ do total de calorias.

\subsection{Extensão dos alimentos usados na merenda}

Por ordem alfabética, foi a seguinte:

Açúcar, Aromatizantes, Arroz, Aveia, Banana, Biscoito, Bolo, Canjica, Carne, Chocolate em pó, Fubá, Geléia, Legumes, Leite, Macarrão, Margarina, Ovo, Pão, Patê, Peixe, Queijo, Salsicha.

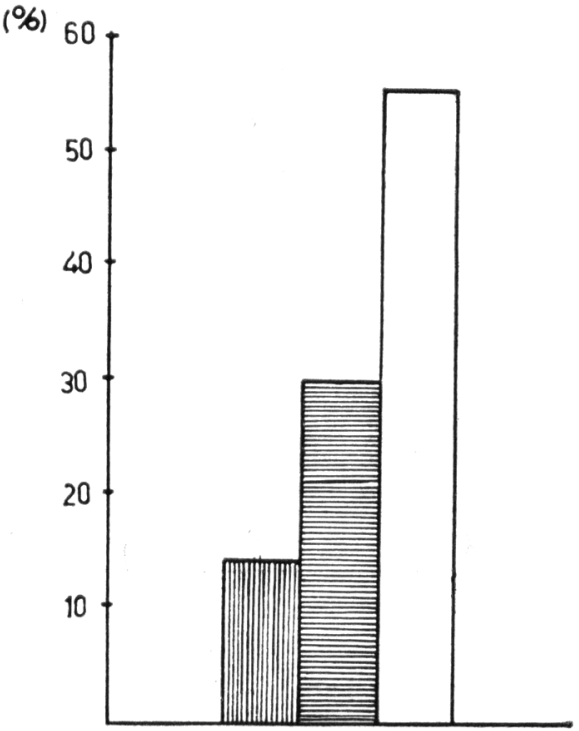

MERENDA - Composição centesimal: Valores médios dos nutrientes básicos das Crianças do Estudo.

\section{DISCUSSAO}

Segundo definição de Dante Costa ${ }^{3}$, a função da merenda é coadjuvar as três outras refeiçōes do dia, corrigindo certas deficiências alimentares comuns em nosso povo.

A necessidade de corrigir as deficiências mais freqüentes é confirmada pela Cartilha da Merenda Escolar ${ }^{1}$, na qual se dá também ènfase aos alimentos ricos em proteinas, minerais e vitaminas.

Uma vez que o propósito deste estudo é analisar a merenda oferecida nas escolas mantidas pela Prefeitura Municipal de São Paulo, no ano de 1974, convém relembrar 
rosenburg, o. A merenda escolar dos alunos clas quatro primeiras séries de nivel I das escolas da Rede Municipal de Ensino de $\mathbf{S}$ ão Paulo. Brasil. Rev. Saúde públ., S. Paulo, 1\%: $55-66, \quad 1978$

¿ assertivat de Rusenburg, ${ }^{11}$ sob cuja direção a merencla foi, na época, organizada:

"A qualidade da merenda distribuída ainda muito se afasta do ideal proposto, isto é, oferecer a cada escolar o equivalente a $1 / 4$ das suas necessidades alimentares diárias, em todos us elementos nutritivos".

Diante da impossibilidade de atingir as metas desejáveis, foi dada uma ênfase especial ao caráter supletivo dessa refeição, tendo en vista as deficiências alimentares mais comuns no regime dietético domiciliar. Em conseqüência, a cobertura calórica proporcionada pelos hidratos de carbono, é freqüentemente, na merenda, inferior à dada pelos lípides e prótides, ou seja, pelos elementos mais escassamente representados na alimentação da criança de classes desfavorecidas.

Escolas houve em que o cardápio da merenda, devido a certas contingências, como a falta de água, se limitou a um ovo cozido. Trata-se de um tipo de refeição que fornece um minimo de calorias, mas, por outro lado, provè à criança uma quantidade de proteinas da melhor qualidade, igual a 5,65 gramas, e de lipides, igual a 4.9 gramas.

$F$ indiscutivel que esse tipo de merenda, apesar de pobre em calorias, é valioso em seu valor supletivo, pelo menos naqueles inúmeros casos em que, no desjejum do escolar, os hidratos de carbono prevalecem largamente sobre os demais componentes.

Em vista desses argumentos, explica-se porque a cobertura calórica da merenda, em relação às necessidades diárias, não chegou, na totalidade dos casos, a cobrir $1 / 4$ dessas necessidades (Tabela 2).

Entretanto, ainda em relação às exigências diárias, a quota protidica superou, em muito, a calórica, uma vez que, em $63,7 \%$ dos casos, ela foi igual ou superior a $1 / 4$ daquelas exigências (Tabela 4). Vê-se, portanto, que a meta proposta foi alcançada ou superada na grande maioria da população visada.
Quanto aos lipides, bastante prejudicados no desjejum,1'2 eles parecem ter desempenhado significativo papel na merenda e uma parte apreciável do seu total calórico foi devida a esse componente. Tal fato é contirmado quando se considera que, a um valor médio absoluto alto, ou seja, 10,36 $\mathrm{g}$ (Tabela 5), em relação aos valores apresentados em seis tipos de merenda considerados satisfatórios pela Campanha Nacional de Alimentação Escolar (Prado, H.". 1973), correspondeu uma distribuição na qual $54,7 \%$ da população estiveram muito próximos desse valor ou o ultrapassaram (Tabela 9).

$\mathrm{Na}$ composição centesimal (Tabela 10), revela-se, quanto aos valores médios, uma distribuição bastante harmoniosa dos nutrientes, o equilibrio relativo entre os componentes sendo mais acentuado na merenda do que no desjejum. (Ver Fig.)

Quanto à extensão dos alimentos, a lista pode ser considerada ampla, nela comparecendo alimentos de alto valor nutritivo e de grande aceitação por parte da criança.

A variedade maior de alimentos usados no desjejum ${ }^{1:}$ pode ser explicada pela presença de gêneros que contribuiram com pouco ou quase nada para torná-lo nuais nutritivo. $\mathrm{Na}$ verdade, alguns deles muitas vezes tomaram o lugar de alimentos que podem ser considerados básicos na primeira refeição. Por exemplo, os refrigerantes, invariavelmente comparecem numa colocação que, sem dúvida, compete ao leite. É evidente ai o desconhecimento de regras primárias de alimentação que muitas vezes atuou tão negativamente quanto o fator econômico, no empobrecimento da primeira refeição.

Aceita como indiscutivel a importância da merenda na sua contribuição para o aumento de peso e de estatura do escolar ${ }^{11}$, ela pode ainda ser considerada sob vários outros aspectos. Um deles refere-se ao seu papel substitutivo da primeira refeição, para a criança que vai à escola pela manhã, quando essa primeira refeição é omitida. 
ROSENBURG, O. A merenda escolar dos alunos das quatro primeiras séries de nível I das escolas da Rede Municipal de Ensino de Sáo Paulo, Brasil. Rev. Saúde públ., S. Paulo, 12: $55-66,1978$.

Parte dos estudos de lowa2, feita com adultos, refere-se especificamente a essa possibilidade, diante de um tipo de refeição que poderia, dentro de certos limites, ser considerado como um equivalente da merenda oferecida pela manhã. Trata-se de uma refeição pequena, ou lanche, tomado entre as primeiras horas da manhã e o almoço.

É importante frisar a expressão "certos limites", uma vez que esse lanche, no caso, foi representado por uma refeição não planejada, constituida apenas por alimentos leves, tais como café, biscoitos, doces, balas e congêneres, e escolhidos à vontade pelos integrantes do grupo experimental. Estes eram indivíduos adultos, que passaram a executar as suas atividades rotineiras, pela manhã, sem consumir alimento de qualquer espécie, como desjejum.

Nessa parte das experiências, verificou-se que, ainda que essa pequena refeição intercalada no periodo matinal não substitua un desjejum adequado, no que se refere à capacidade para o trabalho físico ou mental, a sua inclusão, no caso da falta do desjejum, resultou em vantagem, no rendimento, para $45 \%$ dos individuos.

Outro aspecto a ser considerado na merenda, é o da sua influência sobre as consequiências da fome nas últimas horas matinais, fome esta que será tanto maior quanto mais escasso o desjejum.

Read1a (1973), estabelece que "a fome não altera as estruturas neurológicas. Entretanto, ela pode alterar o aprendizado, diminuindo a receptividade individual e a capacidade de aproveitamento de novas experiências".

Orrs, na Inglaterra, em 1928, é um exemplo de um dos primeiros esforços no sentido de correlacionar alimentação na escola e rendimento escolar. Seu estudo, feito em mais de 6.000 crianças de 5 a 14 anos, sugere que o desempenho na sala de aula, e as notas dos exames, melhoraram em conseqüência de uma "pausa para o leite", o mesmo não ocorrendo em grupo de escolares que receberam biscoitos em lugar do leite.

Aproximadamente na mesna época (1931), Laird e col.6 realizaram uma observação sobre a fome em escolares que não mostravam sinais clínicos de desnutrição. De modo geral, nos alunos privados de un lanche, às $9: 30$ horas da manhā, à base de leite, foram constatados maior nervosismo, sensação de fome, fatigabilidade, e menor concentração, persistência e sociabilidade do que o grupo controle, que o recebia.

Após a Il Grande Guerra, várias comunicações mencionam o efeito benéfico de programas de alimentação no desempenho escolar. Infelizmente, dados minuciosos para consubstanciar essas observações não foram apresentados, ${ }^{4,5}$, Read $^{10}$, porém, comentando esses trabalhos, declara:

"Muito do que se diz sobre fome e comportamento na sala de aula são relatórios altamente subjetivos ou não cientificos, de professores e pais. Entretanto. somados todos, eles indicam que os programas alimentares diminuem a sonolência, a apatia e determinam melhora nas atitudes, atenção e rendimento escolares".

É oportuna também uma referência aos estudos de lowa² relativa aos efeitos de uma pequena refeição intercalada no período da manhã, quando ela sucede a um desjejum tido como adequado. Em tal caso, chegaram os pesquisadores à seguinte conclusão: "Na maior parte dos indivíduos, a intercalação de uma pequena refeição no período da manhã, quando um desjejum conveniente é proporcionado, acrescenta virtualmente nada à capacidade de desempenho".

Tomados, como ponto de referência, os escolares que participaram deste estudo p que compareceram às aulas com o suprimento alimentar conferido pelo desiejum aqui analisado, chega-se à conclusão de que a merenda oferecida a essas crianças desempenha realmente funções múltiplas. Em primeiro lugar, supletiva, pelo menos em relação ao desjejum que, principalmente para a criança que freqüenta a escola pela 
ROSENBURG, O. A merenda escolar dos alunos das quatro primeiras séries de nivel I das escolas da Rede Municipal de Ensino de São Paulo, Brasil. Rev. Saúde públ., S. Paulo, 12: $55-66,1978$.

manhã, é de suma importância. Trata-se, no caso, de alunos que vão enfrentar, após a primeira refeição ou sem ela, um periodo de jejum de no mínimo quatro horas, durante o qual, ao menos três, serão de trabalho mental intensivo. Em segundo lugar, substitutiva, quando há omissão do desjejum. E, em terceiro lugar, educativa. A qualidade dos alimentos oferecidos à criança é, por si só, uma sugestão quanto ao valor nutricional dos gêneros e à elaboração de um cardápio racional.

O estudo comparativo levado a efeito entre as zonas periférica e intermediária, relativo ao desjejum, foi de molde a confirmar as condições mais precárias da zona perifériça, no que se refere às condições de alimentação. Entretanto, a natureza das deficiências encontradas numa e noutra região nâo parece diferir, qualitativa e mesmo quantitativamente, a ponto de indicar a necessidade de modificar a estrutura da merenda, segundo ela se destine a uma ou a outra zona.

Novos esquemas talvez se imponham, por exemplo, no que se relaciona ao horário em que essa refeição é oferecida. Mas, é preciso salientar, as conclusões desse tipo competem a outras áreas e escapam à finalidade deste estudo.

\section{CONCLUSOES}

1. O teor de calorias, na merenda escolar oferecida aos alunos estudados, no ano de 1974, foi, em média, igual a $13,50 \%$ das necessidades diárias, segundo a idade e o sexo, e o consumo mais frequiente situou-se na classe correspondente a $15-20 \%$ dessas necessidades.

2. O teor de proteínas foi, em média, igual a $28,64 \%$ das necessidades diárias, e o consumo mais freqüente situou-se na classe correspondente a $25-30 \%$ dessas necessidades.

3. O teor de lípides, ou gorduras, foi em média igual a 10,36 gramas, e o consumo mais frequiente situou-se na classe correspondente a $10-20$ gramas.

4. A composição centesimal da merenda, nos seus valores médios, caracterizouse por uma distribuição harmoniosa dos nutrientes e por uma inter-relação mais equilibrada do que a observada no desjejum.

5. Os resultados obtidos no estudo sugerem a necessidade da merenda escolar, tendo em vista a sua função substitutiva, nos casos em que o desjejum é omitido, bem como suplementar ou supletiva, quando o desjejum é insuficiente.

RSPUB9/394

RosenBURG, O. ISchool lunch of first through fourth grade municipal school children in S. Paulo, Brazil..7 Rev. Saúde públ., S. Paulo, 12:55-66, 1978.

ABSTRACT: A population of 380 municipal school children belonging to the first through the fourth grades was studied so as to analyse the nutritional value of the school lunch and its role as a substitutive for or as a complement to breakfast. 1. The average calory intake was $15,50 \%$ of the daily requirements; most frequently it was between 15 and 20\%. 2. The average protein intake was $28,64 \%$ of the daily requirements; most frequently it was between 25 and $30 \%$. 3. The average intake of fats or lipids was 10,36 grammes; most frequently it was between 10 and 20 grammes. 4. The percentual composition of the school meal showed the harmonic distribution of the nutrients which were more adequately interrelated than at breakfast.

UnITERMS: Students, nutrition. Nutrition, S. Paulo, Brazil. School lunch. Breakfast. 
ROSENBURG, O. A merenda escolar dos alunos das quatro primeiras séries de nível I das escolas da Rede Municipal de Ensino de São Paulo, Brasil. Rev. Saúde míbl., S. Paulo, 12: $55-66,1978$.

\section{REFERENCIAS BIBLIOGRÁFICAS}

1. CARTILHA da merenda escolar. 3a. ed. Rio de Janeiro, MEC. Campanha Nacional da Merenda Escolar, 1960.

2. A COMPLETE Summary of the Inwa Breakfast Studies. Chicago, Cereal Tnstitute. 1962.

3. COSTA. D. Merendas escolares. Rio de Janeiro, Serviço de Alimentação da Previdência Social (SAPS), 1948. [Mimeografado]

4 DWYER. J. T. et al. Effects of a schoil snack program on certain aspects of school performance. Fed. Proc., 31: 718. 1972.

5. EDWARDS, C. H. et al. Effect of a dietary supplement on height and weight of children. J. Home Econ., 48:363. 1956.

6. LAIRD. D. A. et al. Nervousness in school children as related to hunger and diet. Med. J. Rec., $134: 494,1931$.

7. NACLE. Z. Assistência alimentar ao escolar e pré-escolar nas unidades edurativas assistenciais $e$ de ensino da Prefeitura do Municipio de São Paulo. In: ENCONTRO GOVERNO-EMPRESA PARA A SOLUÇÁO DO PROBLEMA DAS PROTEINAS, Rio de Janeiro. 1970. Anais. Rio de Janeiro. Comissão Nacional de Alimentação. 1970. p. 199-213
8. ORR, J. B. Milk consumption and the growth of school children. Lancet, 1 : 202-3, 1928.

9. PRADO, $\mathrm{H}$. Como a Campanha Nacional de Alimentação Escolar (CNAE) promove a execução do programa de educação nutricional e assistência alimen. tar ao escolar no Estado de São Paulo. In: SEMANA DE DEBATES SOBRH A ALIMENTAÇÃO ESCOLAR, São Paulo, 1973. São Paulo, Câmara Municipal. 1973. p. 1-35.

30. READ, M. S. Malnutrition, hunger and behavior (Part II - Hunger, school feeding programs and behavior). $J$ Amer, Diet. Ass., 63:386-91, 1973.

11. ROSENBURG, C. P. Merenda escolar e crescimento: observacões em 8189 alunos de 42 escolas da rede municipal de ensino de São Paulo. São Paulo, 1972 [Tese de Doutoramento - Faculdade de Saúde Pública da USP]

12. ROSENBURG, O. O desjejum dos alunos das quatro primeiras séries de nivel $I$ das escolas da Rede Municipal de Ensino de São Paulo, Brasil. Rev. Saúde públ., S. Paulo, 11:465-79, 1977.

13. TISDALL, F. F. et al. The Canadian Red Crosss school meal study, Can. Med. Ass. J., 64:477-89, 1951.

Recebido para publicą̧ão em 19/05/197\% Aprovado para publicação em 14/07/1977 